\title{
Article
}

\section{Low-Intensity Whole-Body Vibration: A Useful Adjuvant in Managing Obesity? A Pilot Study}

\author{
Michele Gobbi ${ }^{1, *(0)}$, Cristina Ferrario ${ }^{2,3}(\mathbb{D})$, Marco Tarabini ${ }^{2}\left(\mathbb{D}\right.$, Giuseppe Annino $^{4} \mathbb{D}^{(}$, Nicola Cau $^{5}$, Matteo Zago ${ }^{3}$, \\ Paolo Marzullo ${ }^{6,7}$ (D), Stefania Mai ${ }^{7}$, Manuela Galli ${ }^{3}$ (D) and Paolo Capodaglio ${ }^{1,8}$ (D)
}

1 Unità di Riabilitazione e Laboratorio di Ricerca in Biomeccanica e Riabilitazione, Istituto Auxologico Italiano, IRCCS, 28824 Piancavallo, Italy; p.capodaglio@auxologico.it

2 Dipartimento di Meccanica, Politecnico di Milano, 20100 Milano, Italy; cristina.ferrario@polimi.it (C.F.); marco.tarabini@polimi.it (M.T.)

3 Dipartimento di Elettronica, Informazione e Bioingegneria, Politecnico di Milano, 20100 Milano, Italy; matteo2.zago@polimi.it (M.Z.); manuela.galli@polimi.it (M.G.)

4 Dipartimento di Medicina dei Sistemi, Università di Roma Tor Vergata, 00133 Rome, Italy; giuseppe.annino@uniroma5.it

5 IRCCS Fondazione Don Carlo Gnocchi, 20100 Milan, Italy; ncau@dongnocchi.it

6 Dipartimento di Medicina Traslazionale, Università del Piemonte Orientale, 28100 Novara, Italy; paolo.marzullo@med.uniupo.it

7 Laboratorio di Ricerche Metaboliche, Istituto Auxologico Italiano, IRCCS, 28824 Piancavallo, Italy; s.mai@auxologico.it

8 Dipartimento di Scienze Chirurgiche, Medicina Fisica e Riabilitazione, Università di Torino, 10126 Torino, Italy

* Correspondence: m.gobbi@auxologico.it

Citation: Gobbi, M.; Ferrario, C.; Tarabini, M.; Annino, G.; Cau, N.; Zago, M.; Marzullo, P.; Mai, S.; Galli, M.; Capodaglio, P. Low-Intensity Whole-Body Vibration: A Useful Adjuvant in Managing Obesity? A Pilot Study. Appl. Sci. 2021, 11, 5101. https://doi.org/10.3390/app11115101

Academic Editor: Mark King

Received: 7 April 2021

Accepted: 26 May 2021

Published: 31 May 2021

Publisher's Note: MDPI stays neutral with regard to jurisdictional claims in published maps and institutional affiliations.

Copyright: (c) 2021 by the authors Licensee MDPI, Basel, Switzerland. This article is an open access article distributed under the terms and conditions of the Creative Commons Attribution (CC BY) license (https:/ / creativecommons.org/licenses/by/ $4.0 /)$.

\begin{abstract}
The use of whole-body vibration (WBV) for therapeutic purposes is far from being standardized and an empirical foundation for reporting guidelines for human WBV studies has only very recently been published. Controversies about safety and therapeutic dosage still exist. The present study aimed to investigate the metabolic and mechanical effects of low-intensity WBV according to the ISO 2631 norm on subjects with obesity. Forty-one obese subjects (BMI $\geq 35 \mathrm{~kg} / \mathrm{m}^{2}$ ) were recruited to participate in a 3-week multidisciplinary inpatient rehabilitation program including fitness training and WBV training. During WBV the posture was monitored with an optoelectronic system with six infrared cameras (Vicon, Vicon Motion System, Oxford, UK). The primary endpoints were: variation in body composition, factors of metabolic syndrome, functional activity (sit-to-stand and 6-min walking test), muscle strength, and quality of life. The secondary endpoints were: modification of irisin, testosterone, growth hormone, IGF1 levels. We observed significant changes in salivary irisin levels, Group $2(p<0.01)$ as compared to the control group, while muscle strength, function, and other metabolic and hormonal factors did not change after a 3-week low-intensity WBV training with respect to the control group. Future studies are needed to further investigate the potential metabolic effect of low-intensity WBV in managing weight.
\end{abstract}

Keywords: obesity; irisin; whole-body vibration; exercise; weight loss; rehabilitation; weight management; muscle strength

\section{Introduction}

Excessive body weight increases mechanical stress to the joints and tissues and induces physical limitations and pain [1], leading to a reduction in physical activity that contributes to the loss of muscle mass and strength. Weight loss is conventionally achieved through dietary modifications [2] behavioral correction, and/or exercise prescription [3]. In individuals with obesity, a modest weight loss (5-10\% of body weight) helps to alleviate cardiovascular risk [2]. However, the success rate of therapy for obesity is very low: dieting may work in the short term, but severe dietary restriction alone reduces muscle mass and 
leads to a decline in physical fitness [4]; traditional exercise, such as aerobic and resistance training, improves heart rate variability, physical strength, and body composition. Pain is one of the major determinants of ceasing physical activity $[1,5]$. Aerobic or resistance exercise can be associated with increased risk of musculoskeletal injuries, thus reducing adherence to exercise prescription [5].

In the last two decades, whole-body vibration (WBV) emerged as an alternative exercise modality for strength training [6]. WBV involves exercising on a vibrating platform. The vibrations mechanically generate rapid variations in the length of the muscle-tendon complex [7], stimulating repetitive eccentric-concentric muscular work and reflexive muscle contractions [8]. WBV was first recognized as an alternative to resistance exercise for its ability to enhance force and power in skeletal muscle [6,9]. On the other hand at a molecular level, vibrations lead to the formation of ROS (reactive oxygen species) including hydrogen peroxide in water and biological fluids [10]. A moderate level of ROS induces the body's positive adaptive responses. At the same time it has been known that a high dosage of ROS leads to a decrease in muscle protein synthesis [11]. A major problem in the field is that the different stimulus intensities and safety of WBV devices are often poorly described [12]. The empirical foundation for reporting guidelines for human WBV studies was published only this year. It established a final 40-item panel of the aspects of WBV studies [13] expanding previous recommendations on the use of WBV [14]. However, vibration can have adverse effects on a number of physiologic systems and concern about potential risks for musculoskeletal [15,16], circulatory and neurological disorders [17]; Raynaud's phenomenon [18] after exposure to WBV is still present in the literature. Vibration thresholds for human exposure during a work shift have been explicated in the International Standards Organization ISO-2631 recommendations and are in use only in the field of occupational medicine [17]. Despite the growth of WBV as a surrogate or supplement to exercise, no similar limits have been set so far for its use in rehabilitation [17]. It is true, however, that exposure to vibration during a rehabilitation session is constrained within some minutes of exercise repeated daily for different training durations, whereas occupational exposure is spread throughout the daily work shift and therefore, comparison between the levels of exposure is difficult.

WBV training modality is characterized by several variables: frequency $(\mathrm{Hz})$, type of vibration (rotating or vertical), amplitude in terms of displacement $(\mathrm{mm})$ or, acceleration $(\mathrm{g})$, exposure time and knee flexion grade, series, number of repetitions, rest period, frequency and duration [19]. In some WBV studies, the acceleration delivered by whole body vibration devices at the plantar surfaces of standing subjects and transmitted through the axial and appendicular skeleton exceeded the safety threshold limit values established by the International Standards Organization ISO-2631 [8,17]. The use of WBV for therapeutic purposes appears, therefore, far from being standardized and caution should be used when using WBV devices providing high vibration levels on patients [17]. In light of those gaps in the knowledge, we decided to investigate whether the use of low vibration intensities that certainly fall within the existing recommended safety limits would induce any benefit in subjects with obesity where weight loss or gain in muscle strength represent clinically meaningful goals.

In fact, some evidence exists that WBV improves body composition [20], muscle strength [6] and cardiovascular function in various populations, including individuals with obesity [21,22]. WBV seems to yield the potential to induce both mechanical and metabolic adaptive responses. From the mechanical point of view, exposure to $20-30 \mathrm{~Hz}$ WBV has shown neuromuscular adaptations $[7,8]$. Evidence that body vibrations slow down fat accumulation and reduce adipogenesis in rats [23] suggests a possible clinical use of WBV in the treatment of obesity. Changes in neuromuscular response, testosterone, and growth hormone concentrations have been observed after WBV [24]. An increase in circulating levels of irisin, favoring the browning of the adipose tissue, testosterone and IGF-1 has also been observed [25]. Scant evidence on the effects of WBV in weight loss and reduction in visceral fat exists [26]. It may cause an increase in lipolysis and energy 
expenditure through enhancement of the aforementioned anabolic hormones $[8,24,25]$. A recent systematic review [19] attempted to define the outcomes of WBV on individuals with obesity, the optimal combination of vibration and exercise, and to identify gaps in the knowledge that may lead to improper use of WBV with consequent harmful effects. It was shown that when combined with dietary intervention, 10 or more weeks of WBV produced significant body weight reduction [26,27] and improvements in lower limb strength $[9,27]$. WBV may also appeal to subjects that are not so prone to engage in regular active exercise as it represents a quick and "passive" training modality.

The present study aimed at investigating whether WBV performed at lower intensities falling within the safety limits recommended by the ISO-2631 would be able to induce any metabolic or mechanical effect in subjects with obesity. The primary endpoints were: changes in body composition, metabolic syndrome, performance and muscle strength. The secondary endpoints were: modification of irisin, testosterone, GH and IGF1 levels.

\section{Materials and Methods}

This is a pilot, randomized, double-blind and controlled clinical study following the guidelines of the Consolidated Standards of Reporting Trials (CONSORT) conducted on patients with obesity (BMI $\left.\geq 35 \mathrm{~kg} / \mathrm{m}^{2}\right)$. An extensive medical screening was performed by a physician who checked inclusion and exclusion criteria. Neither the patients nor the trainer who conducted the training program were blinded. Subjects were randomly assigned to one of the four experimental groups after the initial evaluation. After randomization, 11 subjects were assigned to the WBV Group 1, 10 were assigned to the WBV Group 2,10 were assigned to the first control group (Group 3), 10 were assigned to the second control group (Group 4). We used a customized platform with the capacity to accommodate obese patients (Power club, Ferrara, Italy). One patient in Group 1 dropped out. The baseline data were collected at Pre-T0, T0, and T1. At Pre-T0, we collected biochemical samples, body composition data, and calorimetry of the patients. At $\mathrm{T} 0$, the day before the beginning of WBV training, blood samples for hormonal analysis were collected and the postural and functional tests carried out. The first training session of the protocol (T1) was performed the day after T0. At T1, biological samples of saliva immediately before and after the training session were collected. The samples of saliva collected were assayed by ELISA kit only in those subjects who completed 9 WBV series. All the tests were repeated after 3 weeks of training, at T9, T10, and Post-T10, as reported in the timeline in Figure 1.

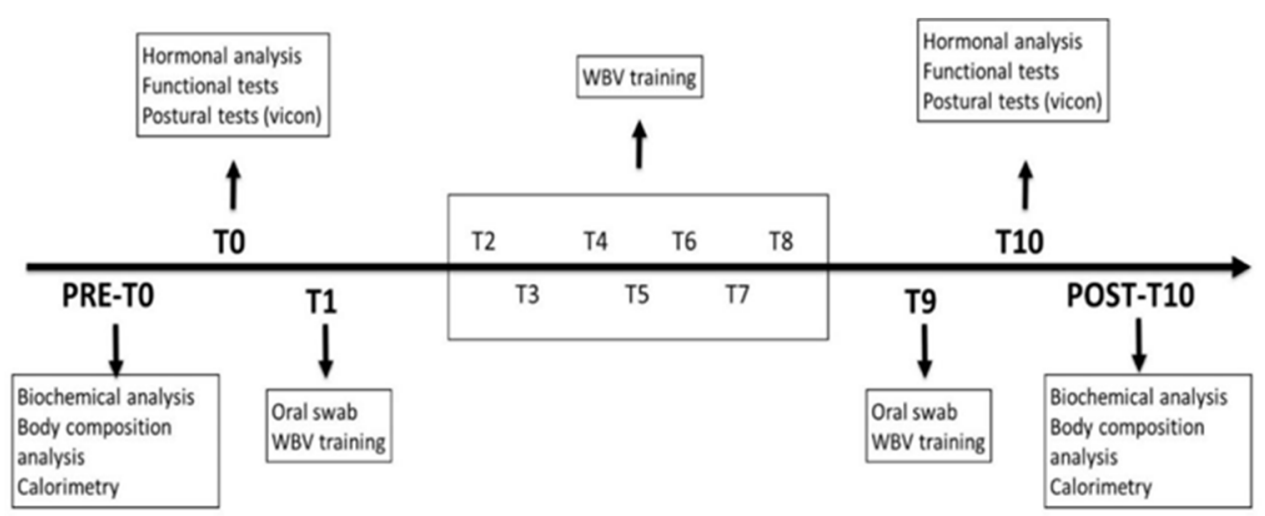

Figure 1. Timeline of the study protocol.

\subsection{Subjects}

Forty-one obese (BMI $\geq 35 \mathrm{~kg} / \mathrm{m}^{2}$ ) subjects admitted to San Giuseppe Hospital, Istituto Auxologico Italiano were recruited to participate in a 3-week multidisciplinary rehabilitation program.

The inclusion criteria for the study were as follows: (1) age between 18 and 60 years; (2) normal $\mathrm{HbA} 1_{\mathrm{c}}$ values. Exclusion criteria were (1) major orthopedic conditions or recent 
orthopedic surgery; (2) neurological conditions; (3) balance disorders; (4) neoplasms; (5) moderate or severe chronic kidney failure; (6) $\mathrm{HbA1}_{\mathrm{c}}>6.4 \%$. Participants were informed about the design of the study and they signed written informed consent before participation. The recruitment, randomization, and allocation of patients is reported in Figure 2. The research was conducted according to the declaration of Helsinki and was approved by the Ethics Committee of the Istituto Auxologico Italiano.

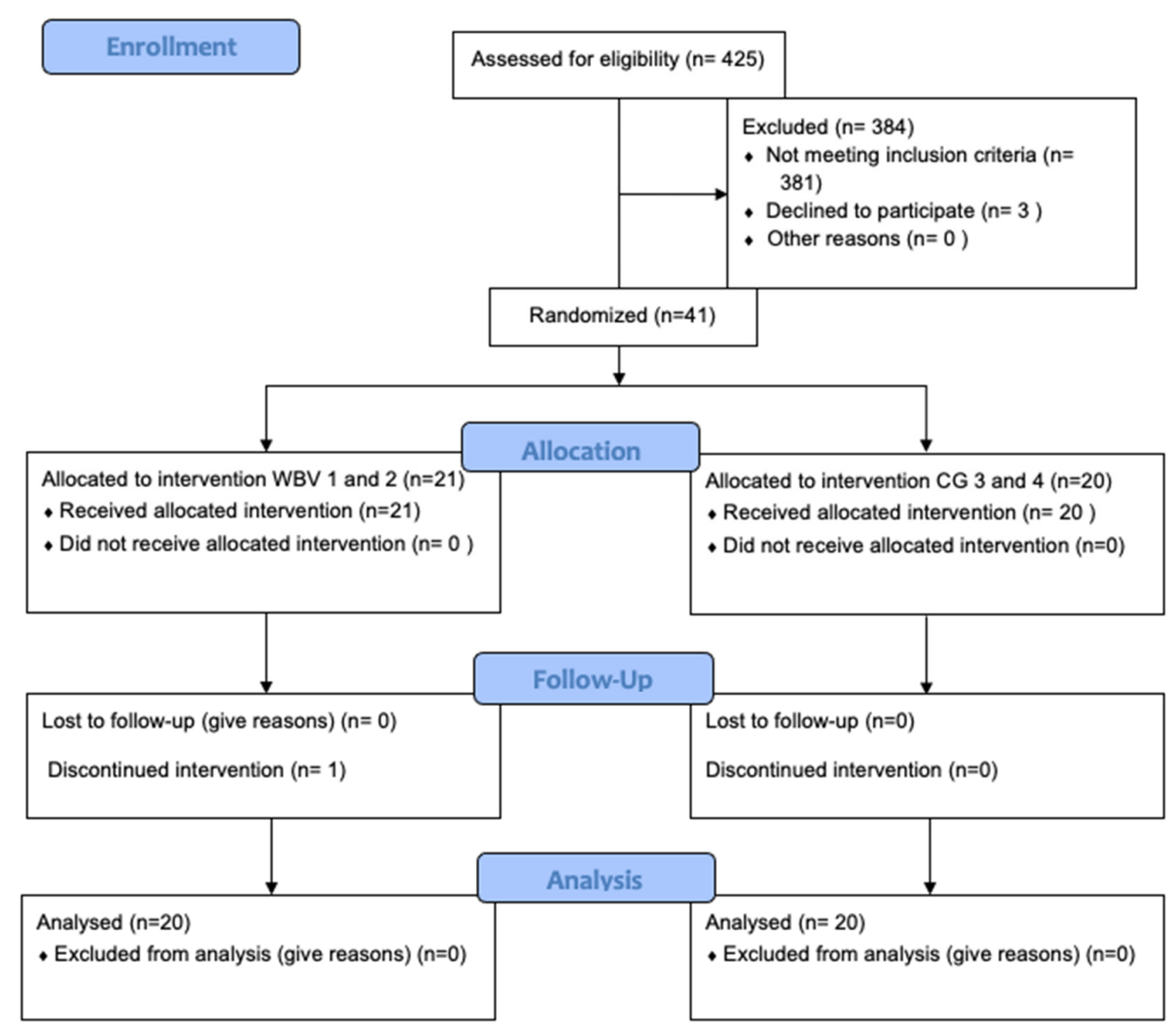

Figure 2. The recruitment, randomization, and allocation of patients.

\subsection{Anthropometric Measurement}

All measurements were performed in the morning, with patients in fasting conditions and undressed. Height was measured to the nearest $0.5 \mathrm{~cm}$, and body weight was measured with a digital scale to the nearest $0.1 \mathrm{~kg}$. BMI was calculated as weight in $\mathrm{kg}$ over height in $\mathrm{m}^{2}$. Waist circumference was measured at the mid-level between the lower rib margin and the iliac crest. Body composition was determined by BIA 101/s (Akern ${ }^{\circledR}$-Firenze, Italy). This technique measures the total fat percentage of the body without making a distinction between peripheral subcutaneous, abdominal subcutaneous, or deep abdominal fat.

\subsection{Metabolic Measurement}

Basal metabolic rate was estimated using a ventilated hood system (Oxycon pro; JAEGER ${ }^{\circledR}$ ).

\subsection{Laboratory Analyses}

A blood sample was taken between 6:00 and 7:00 a.m. to determine fasting levels cholesterol, LDL HDL, triglycerides, calcium, phosphate, alkaline phosphatase, creatine phosphokinase, $\mathrm{HbA}_{\mathrm{c}}$, insulin, glucose, GH, IGF-1, testosterone, cortisol, sex hormonebinding globulin and irisin. The biological samples of saliva were collected in proper tubes (Salivette) immediately before and after the first and last training session from 9.00 a.m. to 
11.00 a.m. All the patients were asked to avoid any activity from $5.00 \mathrm{p} . \mathrm{m}$. of the day before. Lipids and glycemic metabolic profiles were measured with an enzymatic method (Roche Diagnostics $\mathrm{GmbH}$ ). Serum and saliva irisin levels were assessed using a commercially available human ELISA kit EK-067-29 (Phoenix Pharmaceutics, Inc, Burlingame, CA, USA) in accordance with the manufacturer's instructions. This ELISA is specific for human irisin, and quality controls were included in all ELISA measurements with the results falling within the expected range. All samples were analyzed in duplicate. Intraassay and interassay coefficients of variation (CV) of irisin immunoassays were less than $10 \%$ and $15 \%$, respectively, and minimum detectable concentration was $1.5 \mathrm{ng} / \mathrm{mL}$. Results obtained with this commercial kit have been previously validated and published in other papers on the detection of irisin in saliva [28].

\subsection{Muscle Strength and Function}

Handgrip strength was measured to the nearest kilogram using a Jamar hand dynamometer (Sammons Preston, Inc., Bolingbrook, IL, USA). All participants were instructed to maintain an upright standing position, arms down by the side, and hold the dynamometer in the hand without squeezing the arm against the body. The width of the dynamometer's handle was adjusted to the hand size of the participants such that the middle phalanx rested on the inner handle. Participants were allowed to perform one test trial, followed by three trials for the right (HG DX, Hand Grip right hand) and left (HG SX, Hand Grip left hand) hand, and the best measurement was taken for analysis. All participants performed an isokinetic strength test for the lower limbs in two different modalities (Humac Cybex Norm di CSMi). They were first familiarized with the test. Then, the isometric strength of the extensor muscles of the right lower limb was tested at $60^{\circ}$ of knee flexion (ISO EX). After a 3-min recovery, the dynamic strength of the same muscles was tested in the range $90^{\circ}$ to $0^{\circ}$ of knee flexion (ISO DIN EX). Participants were asked to exert their maximal voluntary contraction.

All participants were evaluated with the 6-min walking test (6MWT). Subjects were instructed to walk as fast as they could along an even undisturbed 30-m hospital corridor marked every $5 \mathrm{~m}$; the operator used a lap counter system and the complete distance walked during $6 \mathrm{~min}$ was measured using a tape measure from the nearest marker with colored tape on the floor. Encouragement was given every minute during the test until subject's exhaustion using only standardized phrases as specified in the "ATS Statement: Guidelines for the Six-minute Walk Test". Chest pain, severe dyspnea, physical exhaustion, muscle cramps, sudden gait instability, or other signs of severe distress were additional criteria for stopping the test. The subject's pulse, respiratory rate, blood pressure, and perceived fatigue as assessed on the Borg's scale were measured before the test and at test completion. The distance covered in $6 \mathrm{~min}$ by each subject was used as a variable for the analysis [29].

The following instrumented tests were then performed: Sit-To-Stand (MAXFLEX_SIT2 STAND), Stand-To- Sit (MAXFLEX_STAND2SIT), and 60-s stabilometric test with eyes open and closed on an optoelectronic device (MX Giganet units-Vicon Motion Systems, UK, registered no. 1801446) and a force platform (Kistler Type 5233A- Kistler Instrument Corp., Novi, MI, USA). Before the test, all the participants performed a 5-min warm-up consisting of 3 sets of 10 repetitions of sit-to-stand. All measures were taken at the Research Laboratory in Biomechanics and Rehabilitation of the San Giuseppe Hospital, Istituto Auxologico Italiano.

\subsection{Metabolic Analyses and Diet}

During the study period, all patients underwent a hypocaloric diet based on measured resting metabolic rate using a ventilated hood system (Oxycon pro; CareFusion ${ }^{\circledR}$; Yorba Linda, CA, USA). Caloric intake was $1650 \mathrm{kcal}$ for the first week and the amount in kcal of the resting metabolic rate for the following weeks. Patients were assigned a low-calorie diet equal to their basal metabolic rate with a caloric deficit estimated according to SIOADI 
guidelines between 500-1000 kcal/day. If the dietician assessed that the assigned diet was too low, they adapted it during the following days, to keep it in a range between 500 and $1000 \mathrm{kcal}$ of caloric deficit/day. Meals were administered with a daily frequency of 3 meals. The $\%$ of kcal were divided among the macronutrients as follows: $55-60 \%$ derived from carbohydrates ( $<15 \%$ sugar), $1-1.3 \mathrm{~g}$ of protein $/ \mathrm{kg}$ of ideal weight (weight calculated at BMI 22.5), $25-20 \%$ and deriving from fats ( $<10 \%$ saturated fats). All patients ate 5 portions of fruit and vegetables daily. All macronutrients: carbohydrates, proteins and fats were present in every meal.

\subsection{Fitness Training}

The fitness training program consisted of aerobic low-intensity steady-state training 5 days a week: outdoor walking for $1 \mathrm{~h}$ in the morning and indoor cycling for $25 \mathrm{~min}$ in the afternoon at $65-70 \%$ of maximal measured heart rate (HRmax). Besides, general muscle strengthening exercises for the large muscle groups of the body were performed indoors for $30 \mathrm{~min}$, including warm-up. During indoor activities, all participants were supervised by a skilled physiotherapist to monitor individual heart rate target zones during the training sessions (Pulse Oximeter; Model: MD300C63, Maxtec, UT, USA) in the hospital. Before starting the training course, each patient was instructed to maintain $65-70 \%$ of the maximum heart rate and the intensity level to be maintained was evaluated during the first training session on the cycle ergometer. Heart rate was kept at $65-70 \%$ throughout the cycle ergometer activity. Patients were trained in groups of 8-10 and were monitored by 2 physiotherapists. During the walking activity the patients were asked to maintain a continuous and sustained pace, but they were not monitored. The path and distance were the same for all patients.

The exercise program consisted of 6 bodyweight exercises or with small equipment chosen from 3 exercise categories by the physiotherapist: lower limb (squat, split squat, contralateral forward lunge, deadlift); upper limb (push up, wall push up, wall triceps pushup, dumbbell curl, overhead triceps extension); core (knee plank or plank, back extension, bird dog exercise, knee to chest, crunch) with 3 sets for each exercise and 1-2 min of recovery between sets. No repetitions are mentioned because the physiotherapist instructed patients to cease exercise when a score of 5-6 of fatigue perception on the OMNI scale was reached.

Patients worked in groups of 12-18 people; sessions were scheduled weekly and physiotherapists may have changed according to their worksheets.

\subsection{WBV}

Patients were randomly allocated into four groups and performed WBV training 3 times a week for 3 consecutive weeks (Table 1). All the patients were asked to adopt a semisquat position $\left(60^{\circ}\right.$ knee flexion) on the vibrating platform to minimize vibrations reaching the upper part of the body with feet shoulders' width apart. Group 1 and Group 2 underwent WBV, while Group 3 and Group 4 did not. Patients were asked to hold the bar of the platform in front of them during the session. Visual feedback was provided for training and rest periods. In Group 1, the vibration frequency was $30 \mathrm{~Hz}$ for $1 \mathrm{~min}$ followed by a 1-min rest for 6 series. In Group 2, frequency and duration were the same but repeated for 9 series. In Group 3 and Group 4, patients adopted the same position without WBV for 6 and 9 series, respectively. In such a way, the total volume of exercise and exposure to vibration differed between groups. The two control groups were blinded to the use of WBV. 
Table 1. Number of males or females, age, height, body mass and BMI in the four groups are reported.

\begin{tabular}{cccccc}
\hline Group & N (M/F) & Age [years] & Height $[\mathbf{c m}]$ & Body Mass $[\mathbf{k g}]$ & BMI $\left[\mathbf{k g} / \mathbf{m}^{2}\right]$ \\
\hline 1 & $11(6 / 5)$ & $42.7(13.0)$ & $168.5(10.5)$ & $124.5(19.3)$ & $44.2(7.1)$ \\
2 & $10(5 / 5)$ & $38.5(12.3)$ & $165.7(9.1)$ & $118.3(16.1)$ & $43.2(6.4)$ \\
3 & $10(5 / 5)$ & $42.7(9.6)$ & $168.2(7.7)$ & $132.5(18.3)$ & $46.8(5.2)$ \\
4 & $10(5 / 5)$ & $48.0(9.4)$ & $167.2(10.6)$ & $123.6(27.0)$ & $43.9(7.2)$ \\
\hline
\end{tabular}

The posture was monitored with an optoelectronic system with 6 infrared cameras (Vicon, Vicon Motion System, Oxford, UK) and reflecting markers positioned on the hip, knee, ankle, and the shoulders as shown in Figure 3.

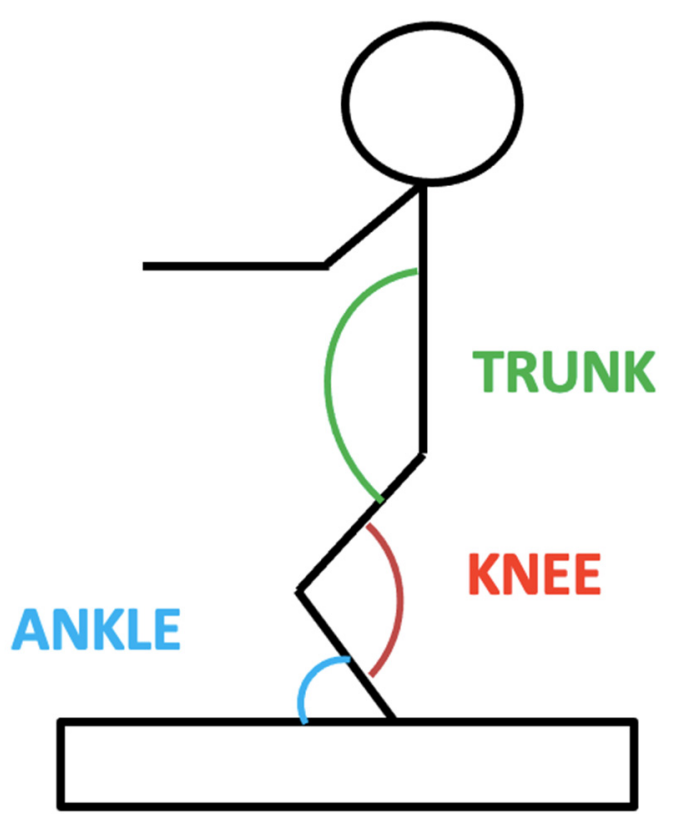

Figure 3. Angles used for controlling posture during the stimulation.

The level of exposure to vibration used was weighed according to the ISO 2631 norm and normalized to an 8-h exposure.

\subsection{Statistical Analysis}

The statistical analysis was performed using Minitab ${ }^{\circledR}$ (version 18.1, State College, PA, USA). A repeated measure ANOVA was performed on the data with the within-subject factor of Time (pre-and post-treatment) and the between-subject factor of Group (group 1 vs. group 2 vs. group 3 vs. group 4). Post hoc tests were performed where appropriate by applying Fisher's correction for the significance threshold. Measures of effect size were provided ad partial eta-square $\left(\eta^{2}\right)$ : a value of 0.01 was considered as a small effect, 0.06 medium effects and 0.14 large effects. A significance level of $\alpha=1 \%$ was implemented throughout.

\section{Results}

Out of the total sample of 41 subjects, 21 were men and 20 were women. The age and anthropometric characteristics of the four study groups at baseline are shown in Table 1.

Baseline characteristics were not significantly different between groups.

The vibration levels used in our protocol were lower than the recommended threshold according to the current EU legislation (Directive 2002/44/EC for-vibration).

The whole picture of the parameters measured in this study is reported in the following tables. In Table 2 the mean and the standard deviations of metabolic and body composition characteristics of the four groups are reported, and tables are divided into 
metabolic (Table 3). The remaining Table 4 the hormonal components are reported, and hormonal (Table 5).

Table 2. Mean and standard deviation of metabolic and body composition characteristics of the four groups. PAS, systolic blood pressure; PAD, diastolic blood pressure; FC, heart rate; FFM, fat free mass in $\mathrm{Kg}$; FFM\%, fat-free mass in \%; CHO, total cholesterol; HDL, cholesterol; LDL, cholesterol; HB1Ac, glycated hemoglobin; insulin; glucose.

\begin{tabular}{|c|c|c|c|c|c|}
\hline \multirow{2}{*}{ Variable } & & Group 1 & Group 2 & Group 3 & Group 4 \\
\hline & & Mean (SD) & Mean (SD) & Mean (SD) & Mean (SD) \\
\hline \multirow{2}{*}{ Mass [kg] } & Post & 118.45 (18.29) & $111.28(14.26)$ & $125.22(16.29)$ & $117.92(23.89)$ \\
\hline & Pre & $124.47(19.28)$ & 118.27 (16.05) & $132.5(18.32)$ & $123.61(26.96)$ \\
\hline \multirow{2}{*}{ BMI $\left[\mathrm{kg} / \mathrm{m}^{2}\right]$} & Post & $41.82(5.28)$ & $53.90(42.10)$ & $44.28(4.96)$ & 41.95 (6.48) \\
\hline & Pre & $44.23(7.05)$ & $43.21(6.40)$ & $46.80(5.21)$ & 43.89 (7.18) \\
\hline \multirow{2}{*}{$\begin{array}{c}\text { Abdomen } \\
\text { circumference }[\mathrm{cm}]\end{array}$} & Post & 115.30 (11.37) & $124.50(8.82)$ & $132.40(10.18)$ & $130.8(17.92)$ \\
\hline & Pre & $120.60(11.63)$ & $126.70(9.51)$ & $135.20(10.40)$ & 134.05 (17.89) \\
\hline \multirow{2}{*}{ PAS [mm/hg] } & Post & $123.64(10.98)$ & $120.50(6.85)$ & $130.00(12.25)$ & $119.44(12.86)$ \\
\hline & Pre & 137.73 (19.15) & $137.50(19.61)$ & $144.00(16.47)$ & $142.00(15.49)$ \\
\hline \multirow{2}{*}{ PAD [mm/hg] } & Post & $78.64(6.74)$ & $76.00(5.16)$ & $85.00(5.00)$ & 75.56 (8.82) \\
\hline & Pre & $80.00(8.94)$ & $84.50(10.66)$ & $92.50(17.20)$ & 87.00 (8.23) \\
\hline \multirow{2}{*}{$\mathrm{FC}[\mathrm{bpm}]$} & Post & $72.55(8.38)$ & $76.70(9.37)$ & $76.11(7.94)$ & 77.78 (9.01) \\
\hline & Pre & 85.82 (14.07) & $83.20(9.91)$ & 88.60 (15.99) & $82.90(6.54)$ \\
\hline \multirow{2}{*}{ FFM [kg] } & Post & $66.33(16.05)$ & $62.11(13.01)$ & $68.42(14.37)$ & $66.24(14.29)$ \\
\hline & Pre & 67.98 (17.73) & $64.70(12.65)$ & $70.96(16.46)$ & 66.48 (16.75) \\
\hline \multirow{2}{*}{ FFM [\%] } & Post & $55.45(7.08)$ & $55.55(8.80)$ & $54.06(7.88)$ & $56.70(5.45)$ \\
\hline & Pre & $54.34(7.9)$ & $54.91(7.82)$ & $53.50(7.57)$ & $54.03(6.95)$ \\
\hline \multirow{2}{*}{$\mathrm{CHO}[\mathrm{mg} / \mathrm{dL}]$} & Post & $147.00(47.9)$ & $153.30(28.11)$ & $171.10(26.61)$ & $146.40(40.20)$ \\
\hline & Pre & $200.60(42.6)$ & $185.50(25.89)$ & $180.90(34.20)$ & $201.30(27.29)$ \\
\hline \multirow{2}{*}{ HDL [mg/dL] } & Post & 39.09 (10.25) & $34.60(8.26)$ & $37.90(8.76)$ & $38.60(5.46)$ \\
\hline & Pre & $42.36(9.98)$ & 37.50 (7.35) & $40.60(9.06)$ & $44.80(7.57)$ \\
\hline \multirow{2}{*}{$\mathrm{LDL}[\mathrm{mg} / \mathrm{dL}]$} & Post & $115.2(54.1)$ & $100.70(22.02)$ & $120.60(23.57)$ & $91.40(38.4)$ \\
\hline & Pre & $143.2(41.4)$ & 131.60 (20.93) & $126.90(33.70)$ & $140.30(20.72)$ \\
\hline \multirow{2}{*}{$\mathrm{HbA1}_{\mathrm{c}}[\%]$} & Post & $5.34(0.34)$ & $5.41(0.38)$ & $5.43(0.28)$ & $5.62(0.46)$ \\
\hline & Pre & $5.51(0.29)$ & $5.52(0.34)$ & $5.57(0.44)$ & $5.78(0.36)$ \\
\hline \multirow{2}{*}{ Insulin $[\mathrm{mU} / \mathrm{L}]$} & Post & $14.32(6.47)$ & $19.03(14.82)$ & $21.11(12.52)$ & $15.46(6.29)$ \\
\hline & Pre & $18.69(7.76)$ & $26.82(17.44)$ & $17.58(7.68)$ & $21.94(6.86)$ \\
\hline \multirow{2}{*}{ Glucose [mg/dL] } & Post & $89.27(8.46)$ & $86.00(6.55)$ & $90.10(4.58)$ & $90.40(8.22)$ \\
\hline & pre & $92.45(5.56)$ & $102.40(25.05)$ & $90.20(5.12)$ & $97.40(8.46)$ \\
\hline
\end{tabular}


Table 3. Metabolic and body composition characteristics of the four groups and relative significance levels and effect size (partial $\eta^{2}$ ). Statistically significant data are highlighted in bold. PAS, systolic blood pressure; PAD, diastolic blood pressure; FC, heart rate; FFM, fat free mass in Kg; FFM\%, fat-free mass in \%; CHO, total cholesterol; HDL, cholesterol; LDL, cholesterol; HB1Ac, glycated hemoglobin; insulin; glucose.

\begin{tabular}{|c|c|c|c|c|}
\hline Variable & Factor & $\mathbf{F}$ & $P$ & Partial $\eta^{2}$ \\
\hline \multirow{3}{*}{ Mass [kg] } & Time & 2.26 & 0.14 & 0.03 \\
\hline & Group & 1.74 & 0.17 & 0.07 \\
\hline & Group $\times$ Time & 0.01 & 0.99 & 0.0003 \\
\hline \multirow{3}{*}{ BMI $\left[\mathrm{kg} / \mathrm{m}^{2}\right]$} & Time & 0.08 & 0.78 & 0.001 \\
\hline & Group & 0.58 & 0.63 & 0.02 \\
\hline & Group $\times$ Time & 0.86 & 0.47 & 0.034 \\
\hline \multirow{3}{*}{$\begin{array}{l}\text { Abdomen } \\
\text { circumference }[\mathrm{cm}]\end{array}$} & Time & 1.43 & 0.24 & 0.02 \\
\hline & Group & 6.59 & 0.001 & 0.22 \\
\hline & Group $\times$ Time & 0.06 & 0.98 & 0.002 \\
\hline \multirow{3}{*}{ PAS [mm/hg] } & Time & 25.8 & $0.29 \times 10^{-5}$ & 0.26 \\
\hline & Group & 1.09 & 0.36 & 0.04 \\
\hline & Group $\times$ Time & 0.35 & 0.79 & 0.01 \\
\hline \multirow{3}{*}{ PAD [mm/hg] } & Time & 11.24 & 0.001 & 0.14 \\
\hline & Group & 3.95 & 0.01 & 0.04 \\
\hline & Group $\times$ Time & 1.02 & 0.39 & 0.04 \\
\hline \multirow{3}{*}{ FC $[b p m]$} & Time & 15.3 & $0.21 \times 10^{-3}$ & 0.17 \\
\hline & Group & 0.32 & 0.81 & 0.01 \\
\hline & Group $\times$ Time & 0.75 & 0.53 & 0.03 \\
\hline \multirow{3}{*}{ FFM [kg] } & Time & 0.27 & 0.61 & 0.004 \\
\hline & Group & 0.57 & 0.64 & 0.02 \\
\hline & Group $\times$ Time & 0.03 & 0.99 & 0.001 \\
\hline \multirow{3}{*}{ FFM [\%] } & Time & 0.57 & 0.45 & 0.008 \\
\hline & Group & 0.18 & 0.91 & 0.007 \\
\hline & Group $\times$ Time & 0.09 & 0.97 & 0.003 \\
\hline \multirow{3}{*}{$\mathrm{CHO}[\mathrm{mg} / \mathrm{dL}]$} & Time & 21.6 & $0.17 \times 10^{-4}$ & 0.24 \\
\hline & Group & 0.15 & 0.93 & 0.007 \\
\hline & Group $\times$ Time & 1.89 & 0.14 & 0.08 \\
\hline \multirow{3}{*}{ HDL [mg/dL] } & Time & 4.01 & 0.05 & 0.05 \\
\hline & Group & 1.7 & 0.18 & 0.06 \\
\hline & Group $\times$ Time & 0.19 & 0.91 & 0.007 \\
\hline \multirow{3}{*}{ LDL [mg/dL] } & Time & 14.1 & $0.34 \times 10^{-3}$ & 0.16 \\
\hline & Group & 0.74 & 0.53 & 0.03 \\
\hline & Group $\times$ Time & 1.29 & 0.28 & 0.05 \\
\hline \multirow{3}{*}{ HB1Ac [\%] } & Time & 3.22 & 0.08 & 0.04 \\
\hline & Group & 2.29 & 0.09 & 0.09 \\
\hline & Group $\times$ Time & 0.03 & 0.99 & 0.001 \\
\hline \multirow{3}{*}{ Insulin [mU/L] } & Time & 2.56 & 0.11 & 0.03 \\
\hline & Group & 1.29 & 0.28 & 0.05 \\
\hline & Group $\times$ Time & 1.13 & 0.34 & 0.04 \\
\hline \multirow{3}{*}{ Glucose [mg/dL] } & Time & 7.71 & 0.007 & 0.09 \\
\hline & Group & 0.74 & 0.53 & 0.03 \\
\hline & Group $\times$ Time & 2.14 & 0.1 & 0.08 \\
\hline
\end{tabular}


Table 4. Mean and standard deviation of the four groups of hormonal components. GH, growth hormone $(\mu \mathrm{g} / \mathrm{L})$; testosterone.

\begin{tabular}{cccccc}
\hline \multirow{2}{*}{ Variable } & Time & Group 1 & Group 2 & Group 3 & Group 4 \\
\cline { 2 - 5 } & & Mean (SD) & Mean (SD) & Mean (SD) & Mean (SD) \\
\hline \multirow{2}{*}{ GH $[\mu \mathrm{g} / \mathrm{L}]$} & Post & $0.29(0.28)$ & $0.36(0.32)$ & $0.40(0.32)$ & $0.58(0.69)$ \\
\cline { 2 - 5 } & Pre & $0.55(0.95)$ & $1.02(2.16)$ & $0.57(0.74)$ & $0.33(0.46)$ \\
\hline $\begin{array}{c}\text { Testosterone } \\
{[\text { nmol/L] }}\end{array}$ & Post & $7.14(6.91)$ & $10.49(12.04)$ & $7.06(7.11)$ & $6.67(6.83)$ \\
\cline { 2 - 6 } & Pre & $6.6(7.28)$ & $8.39(10.18)$ & $8.24(8.40)$ & $5.81(5.75)$ \\
\hline
\end{tabular}

Table 5. Hormonal components of the four groups and relative significance levels and effect size (partial $\eta^{2}$ ). Statistically significant data are highlighted in bold. GH, growth hormone $(\mu \mathrm{g} / \mathrm{L})$; testosterone.

\begin{tabular}{ccccc}
\hline Variable & Factor & F & $\boldsymbol{P}$ & Partial $\eta^{2}$ \\
\hline & Time & 0.23 & 0.63 & 0.003 \\
GH $[\mu \mathrm{g} / \mathrm{L}]$ & Group & 0.39 & 0.76 & 0.02 \\
& Group $\times$ Time & 0.87 & 0.46 & 0.46 \\
\hline \multirow{2}{*}{ Testosterone } & Time & 0.1 & 0.75 & 0.001 \\
[nmol/L] & Group & 0.57 & 0.64 & 0.02 \\
& Group $\times$ Time & 0.13 & 0.94 & 0.005 \\
\hline
\end{tabular}

\subsection{Metabolic Syndrome and Body Composition}

Body weight and BMI did not decrease significantly in all groups with regard to time, group and group $\times$ time after 3 weeks of intervention. Similar results were found in FFM (kg) and FFM (\%), HDL, $\mathrm{Hb}_{1} \mathrm{~A}_{\mathrm{c}}$ and insulin. There was a significant decrease in cardiometabolic components including: systolic and diastolic arterial pressures, heart rate, cholesterol, LDL, and glucose in all groups with regard to time.

\subsection{Muscle Strength and Functional Components}

The strength of the upper limbs tested with a handgrip for the right (HG DX) and left hand (HG SX) did not show any significant difference with regard to time, group or group $\times$ time. Furthermore, the strength of the lower limb tested in static (ISO EX) and dynamic extension (ISO DIN EX) showed non-significant differences in all groups with regard to concerning time, group and group $\times$ time. No significant changes in $6 \mathrm{MWT}$, MAXFLEX_SIT2STAND, and MAXFLEX_STAND2SIT were found.

\subsection{Hormonal Components}

The circulating levels of testosterone and GH (Tables 4 and 5) did not differ in time, group and group $\times$ time. Plasma irisin did not show any differences in time, group and group $\times$ time, whereas change in salivary irisin was observed in Group $2(p<0.01)$ as compared to the control group (Table 6).

The analysis shows increased salivary irisin levels in both groups PRE and POST at $\mathrm{T} 1$ and T9. In particular at time 1, group 2 showed a greater percent delta value $(\Delta \%)$ compared to group 4 .

Table 6. Salivary irisin levels PRE and POST at Time T1 and T9.

T1

T9

\begin{tabular}{ccccccc} 
& \multicolumn{3}{c}{ Salivary Irisin (ng/mL) } & \multicolumn{3}{c}{ Salivary Irisin (ng/mL) } \\
\cline { 2 - 7 } & PRE (SD) & POST (SD) & $\Delta \%$ PRE (SD) & PRE (SD) & POST (SD) & $\Delta \%$ POST (SD) \\
\hline Group 2 & $4.26(3.31)$ & $10.80(5.70)$ & $839.14(1984.41)$ & $2.99(2.10)$ & $8.79(3.80)$ & $478.01(823.44)$ \\
\hline Group 4 & $25.15(0.68)$ & $43.09(40.67)$ & $578.72(2630.94)$ & $22.06(29.46)$ & $71.48(246.77)$ & $509.58(351.21)$ \\
\hline
\end{tabular}




\section{Discussion}

The rationale of the present investigation was to study the effects of WBV exposure within the existing safety limits defined by the ISO-2631 for the Italian occupational standards. To the best of our knowledge, previous studies have investigated only high-intensity WBV associated with dynamic exercise and no randomized controlled trials at different WBV exposures are present in the literature. Our preliminary results showed that lowintensity WBV does not appear effective in improving strength or function in subjects with obesity. Upper and lower limb strength and functional tests (sit-to-stand and stand-to-sit, 6MWT) did not show significant improvements in the two groups undergoing WBV and in the two groups exercising in semisquat without vibration. Previous studies with WBV at higher intensities ( $2.28 \mathrm{~g}$ to over $5 \mathrm{~g}$ ) showed an increase in strength in different populations $[6,9,22,29]$ and an improvement in walking capacity [30]. Only two studies with WBV at lower intensities (0.3-0.4 g) for 3 months showed improvements in the chair-stand test [12] and maximal isometric knee extensors torque and performance as measured by a counter movement jump [9]. Several factors may account for such different results. Firstly, in our program, the patients did not perform any dynamic exercise. Secondly, although the g-force output generated by our vibration platform was of similarly low intensity, the duration of our protocol was only 3 weeks. During the training period we did not modulate variables such as: intensity, volume, exercise selected, rest intervals between sets and frequency, as usually performed in a progressive resistance training program. We opted for a steady low intensity WBV because our aim was to observe whether low intensity vibration certainly falling within the safety recommended limits could affect the musculoskeletal responses of neuromuscular spindles, tendon organs of Golgi and mechanoreceptors or elicit metabolic responses. However, a program duration of 3 weeks may represent too short a period of time to observe muscular adaptation. Furthermore, the strength tests carried out were not specific enough for the proposed exercise, with the patients being tested for lower limb strength in a sitting and not in a standing position, as during training. Additionally, during weight loss the level of protein intake is essential to preserve fat free mass and muscle strength. It is possible that the low-calorie diet with a protein intake of 1-1.3 g protein $/ \mathrm{kg}$ ideal body weight may have compromised the fat free mass of patients. When combined with exercise program, a hypoenergetic diet with an elevated daily intake of protein $(2-3 \times$ RDA) can promote overall improvements in body composition [31].

Several metabolic variables usually included in the definition of metabolic syndrome improved. Systolic and diastolic arterial blood pressure, cholesterol, LDL, and glucose levels decreased significantly, independent of the study group allocation. This result underlines the beneficial effect of physical activity on metabolic variables [32,33]. The lack of a significant difference between the experimental and control group indicates an insufficient training stimulus from the vibration platform. Based on our results, a specific effect of the WBV platform on metabolic improvements cannot be identified. This is in contrast with what has been reported in a long-term WBV protocol on metabolic components [26]. The different results could depend on a different duration of the study protocol, vibration platform intensity, and modality of the exercise, which was isometric in our study and dynamic in the other.

In contrast with the pioneering observations published by Bosco [24], we did not find any difference in either testosterone or $\mathrm{GH}$ levels between groups after the training period, possibly due to the severe degree of obesity of our patients, which blunted the training-induced response of these anabolic hormones [28]. Regarding irisin, a hormone that is associated with the browning of adipose tissue [34] holding a potential dual role as myokine and adipokine in obesity [35], we did not observe changes in its plasma levels after the 3-week program in either subjects exposed to WBV or controls. This lack of effect parallels observations obtained by others in healthy untrained females participating in a 6-week WBV program [25]. Interestingly, we detected an acute change in salivary irisin levels after the nine series of WBV, while no changes occurred in controls. Our decision 
to test salivary irisin was primarily intended to avoid sampling caveats during acute exercise in this severely obese cohort. It has been documented that irisin is produced by the salivary glands and its secretion has been shown to increase in response to acute exercise in moderately obese subjects $[36,37]$. The current findings reveal, therefore, the ability of salivary irisin to respond acutely to WBV bouts and parallel similar results obtained on serum irisin in healthy females subjected to acute vibrating exercise [25]. Whether salivary irisin acts as a function of muscle energy demand or oral nutrient sensing and energy metabolism remains to be investigated and was beyond the scope of this study.

\section{Conclusions}

Isometric low-intensity WBV for 3 weeks does not appear effective in improving strength or function in subjects with obesity due to an insufficient training stimulus from the vibration platform. Further studies will need to investigate longer training duration and/or relatively higher intensities falling within the safety limits proposed in the literature. As for the metabolic effects, an acute change in salivary irisin levels after WBV but not in irisin plasma levels suggests a potential role for this analyte to work as a readily measurable indicator revealing potential dynamic changes in muscle energy. Larger studies are also needed to further investigate the relationship of irisin, exercise capacity and body mass and the potential role of low-intensity WBV in managing weight.

\section{Study Limitations}

A major limitation of our findings was to investigate just one low intensity, therefore no conclusions can be drawn about the minimum effective vibration threshold for obtaining muscle strengthening and/or clearer metabolic effects. As this clinical trial was a pilot with a small number of participants, this study can serve as a basis for sample size estimation in future studies, taking into account the trends pointed out in the results presented. All of the patients were involved in a multidisciplinary rehabilitation program with a hypocaloric diet but individual differences in energy restrictions were not taken into account. An increase in the sample size in a future study should be considered to infer more robust results.

Author Contributions: Conceptualization, P.C., M.G. (Manuela Galli), G.A. and M.T.; data curation, M.G. (Michele Gobbi), C.F. and N.C.; formal analysis N.C., M.Z. and N.C.; investigation, M.G. (Michele Gobbi), C.F., M.Z. and S.M.; methodology, P.C., M.T., M.G. (Manuela Galli), S.M., P.M., N.C., C.F. and M.G. (Cristina Ferrario); project administration, P.C., M.G. (Manuela Galli) and M.T.; writing - original draft, M.G. (Michele Gobbi) and C.F.; writing-review and editing, P.C., M.G. (Manuela Galli), P.M. and M.T. All authors have read and agreed to the published version of the manuscript.

Funding: This research received no external funding.

Institutional Review Board Statement: The study was conducted according to the guidelines of the Declaration of Helsinki, and approved by the Ethics Committee of Istituto Auxologico Italiano (protocol WBV-Obesity, 2017_12_19_03, 19/12/2017).

Informed Consent Statement: Informed consent was obtained from all subjects involved in the study.

Data Availability Statement: Raw data are available in Zenodo.

Conflicts of Interest: The authors declare that there is no conflict of interest regarding the publication of this paper.

\section{References}

1. Zdziarski, L.A.; Wasser, J.G.; Vincent, H.K. Chronic pain management in the obese patient: A focused review of key challenges and potential exercise solutions. J. Pain Res. 2015, 8, 63-77. [CrossRef] [PubMed]

2. Yumuk, V.; Tsigos, C.; Fried, M.; Schindler, K.; Busetto, L.; Micic, D.; Toplak, H. European guidelines for obesity management in adults. Obes. Facts 2015, 8, 402-424. [CrossRef] [PubMed]

3. Andrade, A.M.; Coutinho, S.R.; Silva, M.N.; Mata, J.; Vieira, P.N.; Minderico, C.S.; Melanson, K.J.; Baptista, F.; Sardinha, L.B.; Teixeira, P.J. The effect of physical activity on weight loss is mediated by eating self-regulation. Patient Educ. Couns. 2010, 79, 320-326. [CrossRef] [PubMed] 
4. Janssen, I.; Ross, R. Effects of sex on the change in visceral, subcutaneous adipose tissue and skeletal muscle in response to weight loss. Int. J. Obes. Relat. Metab. Disord. J. Int. Assoc. Study Obes. 1999, 23, 1035-1046. [CrossRef]

5. Guérin, E.; Fortier, M.S. Situational motivation and perceived intensity: Their interaction in predicting changes in positive affect from physical activity. J. Obes. 2012, 2012, 269320. [CrossRef]

6. Roelants, M.; Delecluse, C.; Verschueren, S.M. Whole-body-vibration training increases knee-extension strength and speed of movement in older women. J. Am. Geriatr. Soc. 2004, 52, 901-908. [CrossRef]

7. Cardinale, M.; Bosco, C. The use of vibration as an exercise intervention. Exerc. Sport Sci. Rev. 2003, 31, 3-7. [CrossRef]

8. Rittweger, J. Vibration as an exercise modality: How it may work, and what its potential might be. Eur. J. Appl. Physiol. 2010, 108, 877-904. [CrossRef]

9. Delecluse, C.; Roelants, M.; Verschueren, S. Strength increase after whole-body vibration compared with resistance training. Med. Sci. Sport Exerc. 2003, 1033-1041. [CrossRef]

10. Ghazi, M.; Rippetoe, J.; Chandrashekhar, R.; Wang, H. Focal vibration therapy: Vibration parameters of effective wearable devices. Appl. Sci. 2021, 11, 2969. [CrossRef]

11. Le Moal, E.; Pialoux, V.; Juban, G.; Groussard, C.; Zouhal, H.; Chazaud, B.; Mounier, R. Redox control of skeletal muscle regeneration. Antioxidants Redox Signal. 2017, 27, 276-310. [CrossRef]

12. Beck, B.R.; Norling, T.L. The effect of 8 mos of twice-weekly low- or higher intensity whole body vibration on risk factors for postmenopausal hip fracture. Am. J. Phys. Med. Rehabil. 2010, 89, 997-1009. [CrossRef]

13. Wuestefeld, A.; Fuermaier, A.B.M.; Bernardo-Filho, M.; da Cunha de Sá-Caputo, D.; Rittweger, J.; Schoenau, E.; Stark, C.; Marin, P.J.; Seixas, A.; Judex, S.; et al. Towards reporting guidelines of research using whole-body vibration as training or treatment regimen in human subjects-A Delphi consensus study. PLoS ONE 2020, 15, e0235905. [CrossRef]

14. Rauch, F.; Sievanen, H.; Boonen, S.; Cardinale, M.; Degens, H.; Felsenberg, D.; Roth, J.; Schoenau, E.; Verschueren, S.; Rittweger, J Reporting whole-body vibration intervention studies: Recommendations of the International Society of Musculoskeletal and Neuronal Interactions. J. Musculoskelet. Neuronal Interact. 2010, 10, 193-198.

15. Cardinale, M.; Pope, M.H. The effects of whole body vibration on humans: Dangerous or advantageous? Acta Physiol. Hung. 2003, 90, 195-206. [CrossRef]

16. Garcia-Mendez, Y.; Pearlman, J.L.; Boninger, M.L.; Cooper, R.A. Health risks of vibration exposure to wheelchair users in the community. J. Spinal Cord Med. 2013, 36, 365-375. [CrossRef]

17. Muir, J.; Kiel, D.P.; Rubin, C.T. Safety and severity of accelerations delivered from whole body vibration exercise devices to standing adults. J. Sci. Med. Sport 2013, 16, 526-531. [CrossRef]

18. Stoyneva, Z.; Lyapina, M.; Tzvetkov, D.; Vodenicharov, E. Current pathophysiological views on vibration-induced Raynaud's phenomenon. Cardiovasc. Res. 2002, 57, 615-624. [CrossRef]

19. Zago, M.; Capodaglio, P.; Ferrario, C.; Tarabini, M.; Galli, M. Whole-body vibration training in obese subjects: A systematic review. PLoS ONE 2018, 13, 1-2. [CrossRef]

20. Prisby, R.D.; Lafage-Proust, M.-H.; Malaval, L.; Belli, A.; Vico, L. Effects of whole body vibration on the skeleton and other organ systems in man and animal models: What we know and what we need to know. Ageing Res. Rev. 2008, 7, 319-329. [CrossRef]

21. Sañudo, B.; Alfonso-Rosa, R.; Del Pozo-Cruz, B.; Del Pozo-Cruz, J.; Galiano, D.; Figueroa, A. Whole body vibration training improves leg blood flow and adiposity in patients with type 2 diabetes mellitus. Eur. J. Appl. Physiol. 2013, 113, 2245-2252. [CrossRef]

22. Figueroa, A.; Kalfon, R.; Wong, A. Whole-body vibration training decreases ankle systolic blood pressure and leg arterial stiffness in obese postmenopausal women with high blood pressure. Menopause 2015, 22, 423-427. [CrossRef]

23. Maddalozzo, G.F.; Iwaniec, U.T.; Turner, R.T.; Rosen, C.J.; Widrick, J.J. Whole-body vibration slows the acquisition of fat in mature female rats. Int. J. Obes. 2008, 32, 1348-1354. [CrossRef] [PubMed]

24. Bosco, C.; Iacovelli, M.; Tsarpela, O.; Cardinale, M.; Bonifazi, M.; Tihanyi, J.; Viru, M.; De Lorenzo, A.; Viru, A. Hormonal responses to whole-body vibration in men. Eur. J. Appl. Physiol. 2000, 81, 449-454. [CrossRef] [PubMed]

25. Huh, J.Y.; Mougios, V.; Skraparlis, A.; Kabasakalis, A.; Mantzoros, C.S. Irisin in response to acute and chronic whole-body vibration exercise in humans. Metabolism 2014, 63, 918-921. [CrossRef]

26. Vissers, D.; Verrijken, A.; Mertens, I.; Van Gils, C.; Van De Sompel, A.; Truijen, S.; Van Gaal, L. Effect of long-term whole body vibration training on visceral adipose tissue: A preliminary report. Obes. Facts 2010, 3, 93-100. [CrossRef]

27. Milanese, C.; Piscitelli, F.; Zenti, M.G.; Moghetti, P.; Sandri, M.; Zancanaro, C. Ten-week whole-body vibration training improves body composition and muscle strength in obese women. Int. J. Med. Sci. 2013, 10, 307-311. [CrossRef]

28. Kokkoris, P.; Pi-Sunyer, F.X. Obesity and endocrine disease. Endocrinol. Metab. Clin. N. Am. 2003, 32, 895-914. [CrossRef]

29. Capodaglio, P.; De Souza, S.A.; Parisio, C.; Precilios, H.; Vismara, L.; Cimolin, V.; Brunani, A. Reference values for the 6-Min Walking Test in obese subjects. Disabil. Rehabil. 2013, 35, 1199-1203. [CrossRef]

30. Kawanabe, K.; Kawashima, A.; Sashimoto, I.; Takeda, T.; Sato, Y.; Iwamoto, J. Effect of whole-body vibration exercise and muscle strengthening, balance, and walking exercises on walking ability in the elderly. Keio J. Med. 2007, 56, 28-33. [CrossRef]

31. Jäger, R.; Kerksick, C.M.; Campbell, B.I.; Cribb, P.J.; Wells, S.D.; Skwiat, T.M.; Purpura, M.; Ziegenfuss, T.N.; Ferrando, A.A.; Arent, S.M.; et al. International Society of Sports Nutrition Position Stand: Protein and exercise. J. Int. Soc. Sports Nutr. 2017, 14, 1-25. [CrossRef] [PubMed] 
32. Laaksonen, D.E.; Lindstrom, J.; Lakka, T.A.; Eriksson, J.G.; Niskanen, L.; Wikstrom, K.; Aunola, S.; Keina“ nen-Kiukaanniemi, S.; Laakso, M.; Valle, T.T.; et al. Physical activity in the prevention of type 2 diabetes the Finnish diabetes prevention study David. Br. J. Nutr. 2000, 83. [CrossRef]

33. Laaksonen, D.E.; Lakka, H.M.; Salonen, J.T.; Niskanen, L.K.; Rauramaa, R.; Lakka, T.A. Low levels of leisure-time physical activity and cardiorespiratory fitness predict development of the metabolic syndrome. Diabetes Care 2002, 25, 1612-1618. [CrossRef] [PubMed]

34. Boström, P.; Wu, J.; Jedrychowski, M.P.; Korde, A.; Ye, L.; Lo, J.C.; Rasbach, K.A.; Boström, E.A.; Choi, J.H.; Long, J.Z.; et al. A PGC1a dependent myokine that derives browning of white fat and thermogenesis. Nature 2012, 481, 463-468. [CrossRef]

35. Mai, S.; Grugni, G.; Mele, C.; Vietti, R.; Vigna, L.; Sartorio, A.; Aimaretti, G.; Scacchi, M.; Marzullo, P. Irisin levels in genetic and essential obesity: Clues for a potential dual role. Sci. Rep. 2020, 10, 1-9. [CrossRef]

36. Aydin, S.; Aydin, S.; Kuloglu, T.; Yilmaz, M.; Kalayci, M.; Sahin, I.; Cicek, D. Alterations of irisin concentrations in saliva and serum of obese and normal-weight subjects, before and after $45 \mathrm{~min}$ of a Turkish bath or running. Peptides 2013, 50, 13-18. [CrossRef]

37. Gröschl, M.; Topf, H.G.; Rauh, M.; Kurzai, M.; Rascher, W.; Köhler, H. Postprandial response of salivary ghrelin and leptin to carbohydrate uptake. Gut 2006, 55, 433-434. [CrossRef] 